\title{
MediData: How many types of medical marijuana are for sale?
}

$\mathrm{T}$ ough to say for sure. As of July 14,2014 , there were about 240 cannabis strains mentioned on the websites of Canada's 13 licensed medical marijuana growers. That drops to about 220 if you remove duplicate names. Some strains, however, are sold under different names by different companies. Many of the strains listed on the websites aren't yet in production. According to what the growers say on their websites, they plan to sell the strains detailed in Figure 1 , below.

Of course, these figures could change at any time. Two growers don't yet mention any products on their websites and the lists of strains on other websites change frequently. Canna Farms, in British Columbia, has a lengthy "complete strain list" but had only a few products for sale as of July 14. Many other companies are applying to Health Canada for licences and may offer different types of cannabis.

To check the strains currently listed on the product pages of licensed growers, Google the company names in the list opposite. — Roger Collier, CMAJ

\author{
1. Canna Farms \\ 2. Tilray \\ 3. Delta 9 Bio-Tech \\ 4. MedReleaf \\ 5. Tweed \\ 6. The Peace Naturals Project \\ 7. Whistler Medical Marijuana Co. \\ 8. Organigram \\ 9. Mettrum \\ 10. CanniMed \\ 11. Bedrocan \\ 12. In The Zone \\ 13. Thunderbird Biomedical Inc.
}

CMAJ 2014. DOI:10.1503/cmaj.109-4847

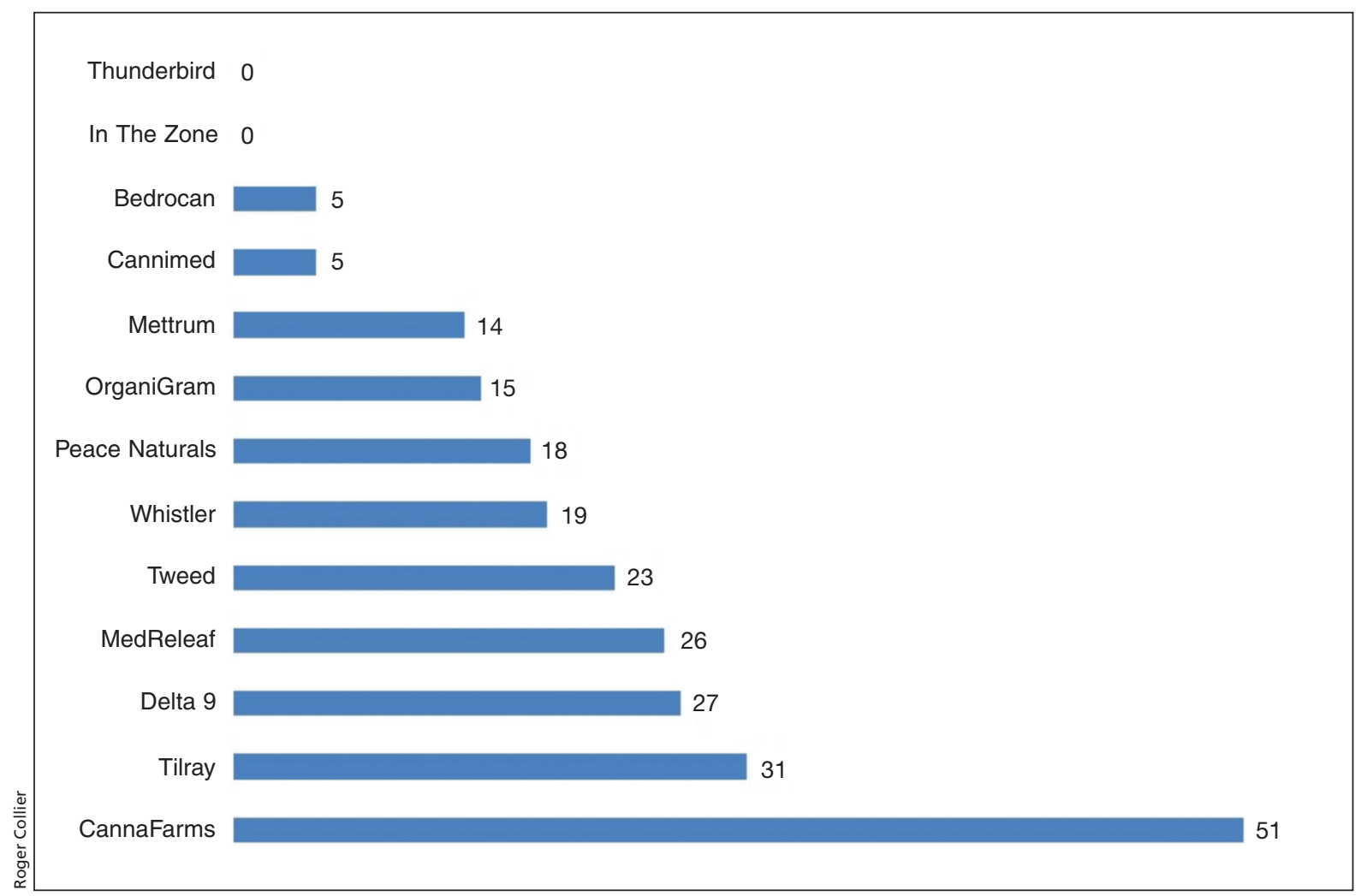

Figure 1: Number of strains of marijuana as advertised on the websites of these growers. 